\title{
THE OPERATIONAL ENVIRONMENT INFLUENCE ON THE DEVELOPMENT LEVEL OF MILITARY STRUCTURES
}

\author{
Constantin GRIGORAŞ \\ “Nicolae Bălcescu" Land Forces Academy, Sibiu, Romania \\ grig_costel67@yahoo.ro
}

\begin{abstract}
The war has not disappeared and will never disappear. It is constantly changing, in perfect correlation with those who created it, the people organized into social structures. It changes according to the changes in the operational environment, influenced, in turn, by the technicalscientific discoveries. All these changes impose a new philosophy of warfare in which the methods of creating and using forces acquire new valences generated by the diversity and the possibilities of access to the new technologies. Knowing the way in which indirect (having the potential) factors influence the fighting capacity of a military structure is just as useful for predicting the outcome of the operation/battle/war. Knowing this assessment, the military decision makers will be able to submit variants and solutions to the political decision maker, who will choose the one that he will appreciate as being the most appropriate.
\end{abstract}

Keywords: operational environment, hybrid war, military operations, structure of the force

\section{Introduction}

The issue of the physiognomy of the military actions of the future has increasingly given rise to the interest of more and more diverse groups of specialists in recent years. If, in the past, it seemed to be an attribute of the militaries, the complexity of the phenomenon has led to its approach by specialists in various fields today. As a science, strategy emerged as a necessity generated by the increasing complexity of military actions. Consequently, in the informational era, this complexity will certainly impose a new chapter in the approach to building, equipping and using military forces.

War, as an objective reality which is part of the lives of people, especially of human communities, must be known and understood as a reality of human existence. In this versatile, uncertain, complex and ambiguous international context, defining the physiognomy of future wars has become an almost feverish concern. As
Toffler pointed out, "the logic, deduction, epistemology - in short, the activity of the human brain and of machinery - is the current premise of military power" [1]. Thus, the physiognomy of conflicts poignantly reveals the need to continuously improve the theoretical and related practical foundation, as well as the approach to the methods and means of action.

The emerging contemporary operational environment will impose a new philosophy of warfare. Factors such as limited resources, asymmetric threats, limiting the collateral damage and losses among noncombatants, the preponderance of actions in the urban environment and the multinational and joint character of military actions will alter the traditional way of generating and regenerating forces, and, in the same manner, the way actions are planned and forces are managed.

At the end of the last millennium, based on their experiences and on a thorough analysis of the operational environment, the 
American specialists developed a new strategic concept. In order to apply it, a complex process started for the transformation of the existing forces "Legacy force" into a party of forces grouped under the name "Objective Force XXI". In the land forces, this process was accomplished through the conversion of small arms infantry forces into initial forces of brigade level (Initial Brigade Combat Team), further grouped into forces of interim brigade level (Interim Brigade Combat Team). At this stage six "STRYKER" type brigades have been created, some of them having already been tested in the latest conflict in the Persian Gulf.

It is very fashionable nowadays to use concepts such as network-based warfare, effect-based operations, fourth generation warfare, network-based operations and hybrid warfare. They are modern concepts, resulting from the need to adapt to a constantly changing operational environment. But the hardest step, from theory to practice, has been made by the Americans for the time being.

\section{Defining elements of the current operational environment}

The current operational environment is extremely fluid, characterized by changes in coalitions, alliances and partnerships, as well as by the emergence and disappearance of some (state, non-state, national and transnational) actors. More and more frequently, the gravity centers are represented by the complex terrain or the urban area having a more or less developed infrastructure and civilian population, which automatically qualifies them as areas of operations. Taking action in these areas of operations adds a humanitarian crisis component to the armed conflict, which will require taking appropriate measures for the management of the population.

In addition to the civilian population, it is worth mentioning the presence in the area of operation of private, non-governmental, regional and international organizations, with their policies and agendas, sometimes favorable to their own forces, sometimes in competition with them. Many of them have enough power and influence to exert strong pressure on what previously were purely military operations.

The importance of the ever more active existence of information organizations, of systems and computerized architectures, private or public, cannot be neglected. The global flow of information, technology, knowledge and power is now creating a favorable environment for all the categories of information operations, information distribution and information warfare. The scientific conquests, the diversity and the possibilities of access to them have led to changes in the way in which the forces are created and used, while at the same time creating conditions favorable to the technological breakthrough. This situation has generated an erosion process that slowly undermines the technological supremacy enjoyed by some advanced countries over the last 20 years.

The cultural and demographic factors that go beyond the borders and internal problems of some countries have made conflict solving a complicated and longlasting process that often requires the operation of changes in the character of operations before the final desirable state is reached. These situations will increase in number and importance.

The military operations of the future will be characterized by combining the possibilities of a force and the use of the environment in a unique operational framework. They will consider using the concept of opportunity derived from environmental conditions to the detriment of the unilateral use of military capabilities, specific to wars of attrition. This is the new paradigm of operations. The specialized literature underlines the fact that these characteristics and their implications have been carefully studied and implemented on a wide scale. 
I am of the opinion that the most important features of present and future military operations in the new operational environments are:

- the fact that they primarily take place in complex terrain and urban environment;

- the enhance of informational warfare/information operations;

- the expanse of operations in the outer space;

- the need to design power outside the national territory and the loss of the invulnerability of one's own territory;

- constraints and limitations in the use of military forces;

- carrying out operations under the conditions of complex, often changing relationships generating uncertainties;

- the rules of engagement are required;

-"live" operation - media;

- carrying out operations with limited resources;
- the ambiguous operational environment; - military operations carried out at a very high rate, with surgical precision of strikes; - dissymmetric operational environment;

- future operations, as well as those of the past and present, will focus on avoiding loss of life;

The principles presented in fig. 1, which identify the physiognomy and typology of the new military or non-military conflicts resulting from the modern impact of the general laws of war and of military conflicts, with today's and perhaps the future society's challenges outline a new type of conflict that is increasingly becoming more diffuse, more disproportionate and hence more difficult to control and manage.

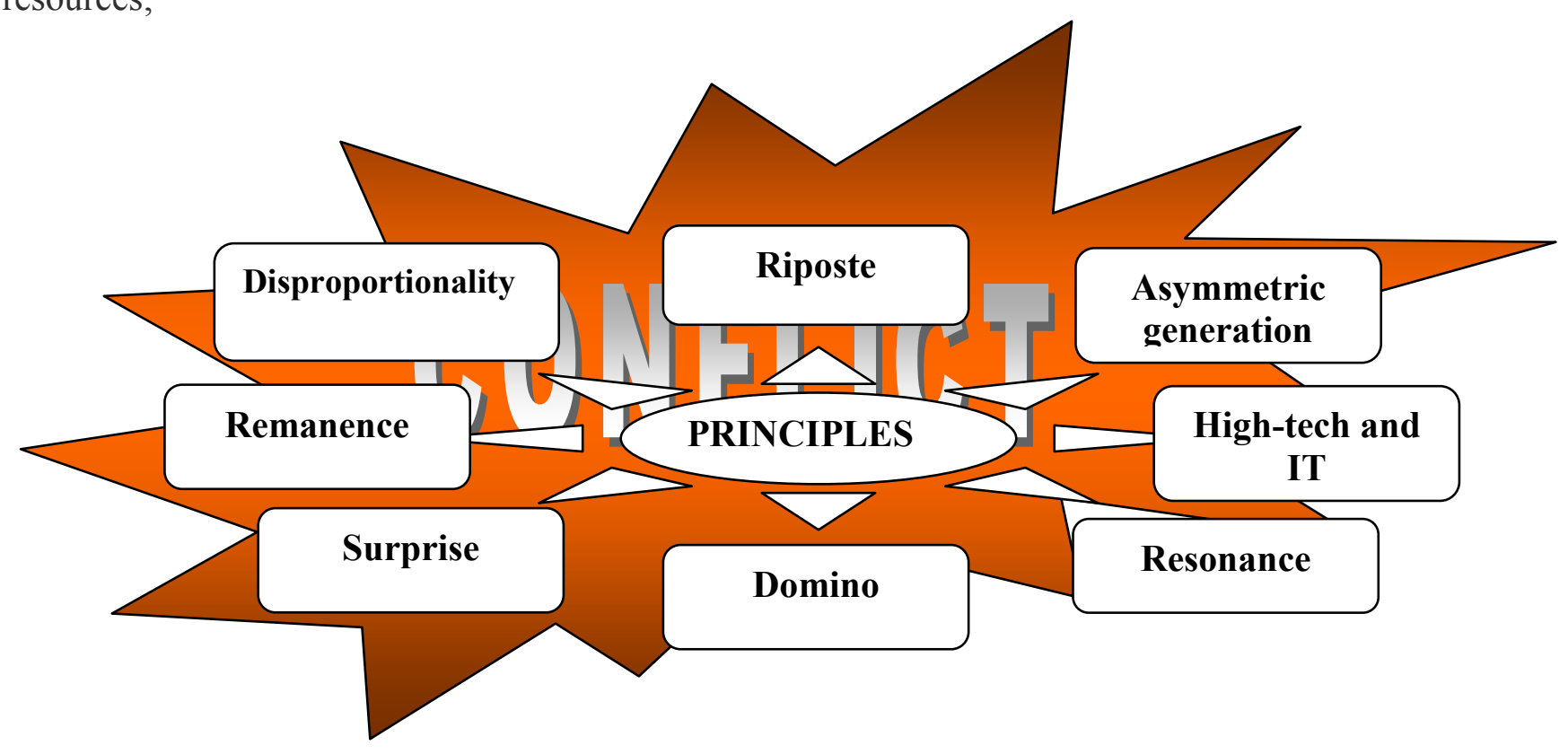

Fig. 1 Principles that identify the physiognomy and typology of the new military or non-military conflicts

Another feature of the operational environment is the confrontation between civilization and non-civilization, one that opposes the one hand stability, democratic values, human rights and market economy, and on the other forces that aim to chaos: organized crime, terrorist structures, drug traffickers, promoters of extremism and intolerance. Not incidentally, the doctrines of certain countries (USA) armed forces may be involved in anti-drug operations, as a form of stability and support operations. 
War was and remains one of the main features of human society transposed by making conflict relations and political, economic and social. In essence, the war remains a catastrophe, a social cataclysm resulting in loss of life, significant material damage and a massive loss in terms of the life and spirituality of a society.

\section{Theories on hybrid war}

Although not new, the phrase "hybrid war" does not yet have a unanimously accepted definition. In 1933, the Russian military theorist Georgi Isserson wrote in his work "The Fundamentals of Depth Operations" that "mobilization must not take place after the war has been declared, but unnoticed attacks must happen a long time before "[2].

In other authors' view, the hybrid war represents "a combination of symmetrical and asymmetrical armed conflicts, in which the intervention forces carry out traditional military operations against military forces and enemy targets, while simultaneously and decisively acting to gain control over the indigenous population in the area of operations through stability operations "[4]. The same approach belongs to the Chief of the General Staff of the Russian Federation, General Gherasimov, who, in an article published in the Russian Defense VPK, underlines the secret use of the regular military forces as the last resort, and the Special Forces appear to be the main means of action, concealed as peacekeeping forces and information operations [5].

The hybrid confrontation goes beyond the physical elements of the conflict, the media and imagistic warfare, where media manipulation and discrediting the opponent can be priorities, and where the integration of information operations with strategic communication programs is as important as the weapon systems on the battlefield. The border between regular war and "new wars" is more and more diffuse, and non-state groups have access to those weapons that once were exclusively state-owned. The amplification of unconventional means, techniques, methods and strategies can lead to a real dilemma of security, in the sense of a manifestation of the tendencies of increasing the power, especially military power, of the states.

The hybrid war, in my opinion, implies a complex engagement in a confrontation, undeclared by the states or other actors, where the one generating the aggression aims at achieving synergic effects through the combined exploitation of societal weaknesses (ethnic tensions, weak and corrupt institutions, economic/energy dependence, etc.) with the military ones, but the latter are not explicitly assumed. The proposed effects can be achieved at all levels of the war.

The hybrid war consists of a combination of conventional and unconventional, lethal and non-lethal capabilities, from different spheres of social life, aiming at gaining a decisive advantage over the opponents.

The hybrid war targets both at the intrastate and the interstate level, and can have extremely various forms of manifestation, integrating regular forces, guerrilla formations, terrorist or criminal elements, and using various weapons and tactics without any regard to the laws of war.

The crisis in Ukraine is the result of the concerted actions of the Russian Federation in order to maintain the sphere of influence and to discredit NATO and the European Union. To this end, Russia has prepared a new type of war, where information operations and the use of Special Forces have played a central role.

The management of the hybrid warfare involves hybrid responses based on the multidimensional approach to conflict, including almost all areas of social life: political, economic, financial, societal, including environmental. The success of the operations is given by the synergy of effects, which can be achieved at all levels of war. Applying the results of knowledge, capitalizing on the human potential, the comprehensive approach, interagency, the 
valorization of intelligence products and, last but not least, multidisciplinary education and training must be priorities.

\section{Criteria for establishing the structure of force}

The process of establishing the structure of force is closely related to the characteristics of the operational environment and the type of mission, or more precisely to the particularities of the missions that these forces will have to fulfill. Planning, as a process, is the outline of a reference model that will later become a standardized model for future structures.

So, the final outcome of the process of establishing the structure of the force will have to meet the previously identified requirements.

Planning the structure of the military force for a particular type of mission is a laborious process that must follow an algorithm that will result in a structure of force that is capable of effectively responding to the needs for which it was created. Thus, we can define a few abovementioned variables, to which the process of setting the force is subjected:

- the dynamic context of the environment in which this process takes place;

- the cause-effect relationship between the factors involved in designing defense;

- the fluctuations that occur in the country's economic development;

- the constant implementation of the process of reform in all areas of activity, including national defense;

- $\quad$ the interaction between the stages of the process of national planning;

- the multitude of guiding documents (programs, actions and measures initiated) on which the planning of defense is based.

We highlight the previously mentioned stages of the process of planning defense, with a view to pointing to the criteria for determining the structure of the force by correlating them with the type of mission. Thus, the process of planning is divided into 5 stages: 1 - elaborating a planning directive; 2 - defining the needs; 3 allocating the needs and setting the objectives; 4 - facilitating the implementation of national planning; 5 examining the results.

For the determination of the structure of the force, the 5 planning steps will be applied for each military operation. At the end of this procedure, the structure needed to meet the initially identified needs will be broadly achieved. By applying the peculiarities specific to that mission, a structure of force will be obtained, which will be able to effectively respond to the challenges for which it was built.

The structuring of the force is frequently addressed according to three different criteria: depending on the threats, the scenarios and the future capacities [6].

a) Depending on the threats. When applying this criterion, the force is framed with the declared purpose of dealing with specific threats. In this respect, intelligence services evaluate the likely threats; the defense and security decision-makers determine the necessary forces and the ability to counteract these threats according to the order of priority. Then hypotheses are formulated according to this priority order in terms of alert and response time, the possibility of concurrent operations and the capabilities required.

b) Depending on the scenarios. This

criterion is no different from the previous one. It is based on a series of generic scenarios defining defense policies and strategies, which are then sorted according to the assigned priority. The capacities are then designed according to each scenario.

c) Depending on future capabilities. This criterion seeks to determine the capacities and forces that will be received to face future threats and to draw on the opportunities of the future. It endeavors to specify the characteristics of the security environment in the future and to determine 
the possible missions, as well as to formulate operational assumptions. Then, various types of force structures are developed, depending on the capabilities required to carry out these tasks.

The process of establishing the structure of force generally follows the following stages:

1. Determination of the elements to be retained for structuring the force (scenarios). The first stage determines the elements that will have to be taken into account in the structuring of the forces or the missions that the defense policies and strategy require.

2. Establishing a priority order for the retained elements and determination of acceptable risks. This stage classifies the elements retained in the order of priority, based on the policy and strategy guidelines. At the same time, it allows to see where the emphasis should be placed and where the risks can be accepted. At this stage the risk levels must be determined. In high priority sectors, only low or moderate risks may be acceptable. In the low priority sectors, higher risks could be accepted. This stage is perhaps the most important, but also the most difficult.

3. Conceiving the components of the structure of the force. Once these elements, as well as the levels of priority and risk have been taken into account for the structuring of the force, the third stage serves to conceive the individual components that will form the structure of the forces (tactical units), which will be compatible with the levels of risk concerned.

4. Considering the multiple use of the same component. This and the next step seek to integrate the various components into a structure of force that can be a valid choice. The first task of the fourth stage is to examine the potential for multiple uses of these components.

5. Integration of rotation requirements. This stage explicitly addresses the issues and matters of rotation. Some requirements must be taken into account, such as the fact that, for a military in mission, there are four others left in the rear.

6. Adjusting the structure according to the creation of forces and the other requirements. This stage deals with the issue of creating forces as bases of recruitment and training, as well as other specific requirements.

7. Modeling and analyzing the structure of the force in order to assess the risk. The last step is to model and analyze the structure of the force resulting from the preceding steps in order to determine whether they correspond, at an acceptable level of risk, to the requirements of each country's policy and strategy.

\section{Conclusions}

To sum up, each criterion has its advantages and disadvantages. That is why the choice of one or the other is made according to the concrete context of the future mission assigned to the respective structure of forces. The reorganization of military structures has been and will continue to be a difficult and often "painful" action, even if it is conducted in peace/normality conditions, and it multiplies its effects even more when it is to be carried out in crisis or war situations.

\section{References}

[1] Alvin Toffler, Power in Motion, Publishing Header, Bucharest, 1995, p.25.

[2] J.N. Nielsen, "Hybrid Warfare", October 07, 2014; https://geopolicraticus.wordpress.com/2014/10/07/hybrid-warfare/ (accessed on April 23, 2015);

[3] James N. Mattis \& Frank Hoffman, Future Warfare: The Rise of Hybrid Wars, U.S. Naval Institute Proceedings Magazine, November 2005, p. 2. 
[4] Colonel John J. Mc Cuen, USA, Retired, Hybrid Wars, Military Review, March-April 2008, the United States Army Combined Arms Center, Fort Leavenworth, Kansas, pp. 107108.

[5] Nielsen J.N., "Hybrid Warfare", October 07, 2014; https://geopolicraticus.wordpress.com/2014/10/07/hybrid-warfare/ (accessed on 23 April 2015). [6] Policies Defense Policy Review: Tackling the Gap between Strategy and Resources http://www.journal.forces.gc.ca/engraph/vol3/no3/pdf/21-28 e.pdf, accessed on 24.04.2011. 